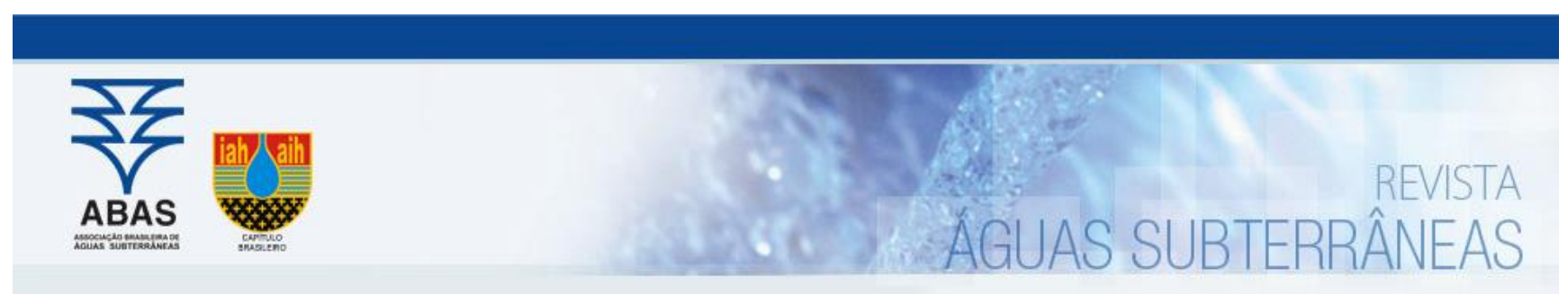

Artigos

\title{
Prognósticos de alterações nas vazões de base como meio de suporte ao gerenciamento de recursos hídricos
}

\author{
Prognostics of changes in base flows as a means of support for water \\ resource management
}

\author{
Guilherme da Silva Ricardo1; Sílvio Luís Rafaeli Neto1; Cláudia Guimarães Camargo Campos¹; Bruno Álvaro Schina1 ${ }^{\circledR}$ \\ 1 Universidade do Estado de Santa Catarina (UDESC), Florianópolis, SC \\ guilhermericardo@terra.com.br, silvio.rafaeli@udesc.br, claudia.campos@udesc.br, bruno@gmail.com
}

Palavras-chave:

Recursos Hídricos.

Hidrologia.

Modelagem hidrológica.

Disponibilidade Hídrica.

Resumo

O efeito das mudanças climáticas pode ser observado nas fases do ciclo hidrológico das bacias hidrográficas. A fase escoamento subterrâneo é uma das mais importantes, pois é a responsável pelo escoamento de base nos cursos d'água em períodos de estiagem. Neste cenário, a captação de água a partir dos reservatórios subterrâneos deverá ser uma alternativa às demandas hídricas. Considerando a relevância da contribuição subterrânea no escoamento total em bacias hidrográficas, este trabalho teve como objetivo avaliar os impactos das mudanças climáticas no escoamento de base de uma bacia hidrográfica da região do centro oeste de Santa Catarina, por meio de evidências constatadas na variação futura (2020 a 2099) das vazões mínimas de referência Q98, Q95 e Q90 e da vazão básica média, em relação ao período base (1977 a 1990). Para isso, as projeções climáticas geradas pelo modelo climático regionalizado ETAHadGEM2-ES para os cenários de mudanças climáticas RCP 4.5 (cenário intermediário) e RCP 8.5 (cenário pessimista), foram aplicadas ao modelo hidrológico HEC-HMS calibrado e validado. As projeções de vazões futuras foram avaliadas para períodos que correspondem aos futuros centrados em 2030, 2050, 2070 e 2090. No cenário mais crítico as projeções hidrológicas para o cenário RCP 8.5 resultaram em reduções percentuais significativas nas vazões de referência $Q_{98}$ e $Q_{95}$ para os períodos centrados em 2030 e 2050 quando comparadas ao período base. Apesar das reducões nas vazões mínimas de referência, a vazão básica média apresentou aumento percentual de 10,3\% e 12,2\% respectivamente. Os resultados apresentados neste estudo são relevantes para o planejamento e implementação antecipada de ações, com objetivo de reduzir os impactos futuros das mudanças climáticas sobre os recursos hídricos no nível de bacia hidrográfica.

Abstract

Keywords:

The effect of climate change can be observed in the phases of the hydrological cycle of watersheds. The groundwater phase is one of the most important, because it is responsible for the baseflow in the rivers in drought period. Considering the relevance of the groundwater contribution to the flow watersheds the objective of this work was to evaluate the impacts of future climate change scenarios on the baseflow in a watershed of the central west region of Santa Catarina State, with evidence of the future situation $\left(2020\right.$ a 2099) in minimum reference flows $Q_{98}, Q_{95}$ and $Q_{90}$ and the average baseflow flow, compared with the base period (1977 to 1990). The climate projections generated by the regionalized climate model ETA-HadGEM2-ES for the climate change scenarios RCP 4.5 (intermediate scenario) and RCP 8.5 (pessimistic scenario) were submitted to the HEC-HMS hydrological model calibrated and validated. Future outflow projections was evaluated for future periods that correspond to the future centerings 2030, 2050, 2070 and 2090. The hydrological projection for the critical situation of RCP 8.5 scenario showed that will be a significant percentage reduction in the reference flows Q98 and Q95 for the future centerings in 2030 and 2050 when compared to the base period. Despite the reductions in reference flows, the average basic flow presented a percentage increase of $10.3 \%$ and $12.2 \%$ respectively. The results presented in this study are relevant to anticipate the planning and early implementation of actions, to reduce the future impacts of climate change on water resources at the watershed level.

DOI: http:/dx.doi.org/10.14295/ras.v34i1.29593

\section{INTRODUÇÃO}

As vazões de base representam as taxas mínimas dos fluxos de água em um curso d’água. 0 estudo das taxas mínimas tem aplicações no abastecimento às populações e aos processos produtivos, na determinação da capacidade de diluição de poluentes dos cursos d’água e na recreação, entre outros. Determinar possíveis alterações nos padrões de comportamen- tos históricos destas vazões possibilita o delineamento de cenários de restrições, em que situações de conflito de uso estejam presentes. Tais cenários são úteis na etapa de prognóstico quando da construção de planos de gerenciamento de recursos hídricos. No Brasil, estes planos são um dos principais instrumentos de gestão destes recursos, sempre aplicados no nivel de uma bacia hidrográfica (BRASIL, 1997). 
As águas subterrâneas têm relevante participação na manutenção do escoamento de base dos rios. Os reservatórios subterrâneos são responsáveis por alimentar o fluxo de água no solo em direção aos rios. Este processo natural garante a regulação das vazões mínimas nos cursos d'água durante períodos secos (WITTENBERG, 2003).

As vazões de base podem ser parametrizadas por meio das vazões mínimas de referência, tais como a Q90, Q95 e Q98 (ZUCCO et al., 2012). Estas representam as vazões no curso d'água que são igualadas ou superadas, respectivamente, em 90, 95 e 98\% do tempo na seção transversal do curso d'água em que foram medidas (ANA, 2013). Estes parâmetros usualmente são adotados por órgãos reguladores nos processos de outorgas de captações e demais usos da água, no âmbito da gestão dos recursos hídricos (JORGE SANTOS; CUNHA, 2013).

Alterações nas estruturas das unidades hidrológicas fundamentais da paisagem (WINTER, 2001) de uma bacia hidrográfica podem provocar alterações no padrão estacionário das vazões de base (JARSJÖ et al., 2012; MAO; CHERKAUER, 2009). De acordo com WINTER (2001), a forma, a geologia e o clima definem estas unidades hidrológicas, nas quais a geologia local determina os padrões dos fluxos subterrâneos. Os fluxos subsuperficiais e subterrâneos interagem com o clima, especialmente com a precipitação e evapotranspiração. Se por um lado os modelos hidrológicos de base física (NETO et al, 2019) procuram representar a fase terrestre do ciclo hidrológico, os modelos climáticos procuram representar os processos da fase atmosférica. Portanto, o prognóstico para o comportamento das vazões de base pode ser realizado com auxílio de modelos hidrológicos de base física, acoplados a modelos de projeções climáticas.

Estudos de projeções futuras para vazões mínimas já foram realizadas em diferentes bacias experimentais. NYENJE; BATELAAN, (2009), por exemplo, avaliaram os impactos das mudanças climáticas nas vazões básicas da bacia Ssezibwa em Uganda. De acordo com os autores, a modelagem aplicada para o período de 2020 a 2080 indicou um aumento na média diária das vazões de base no rio Ssezibwa na ordem de 30 a $90 \%$.

Mais recentemente, o estudo publicado por Ficklin; Robeson; Knouft (2016) avaliou os impactos recentes (1980 a 2010) das mudanças climáticas na vazão de base em bacias nos Estados Unidos, a partir da análise de 674 pontos de controle. 0 estudo mostrou que as variações observadas nas vazões de base têm relação direta com as mudanças climáticas.

Portanto, a magnitude com que a hidrologia subterrânea de uma bacia será impactada pelas mudanças climáticas dependerá do nível de alteração do ciclo hidrológico em cada região, que, deverá variar espacial e temporalmente (MARENGO; TOMASELLA; NOBRE; 2010).

Em 2014, o Painel Intergovernamental sobre Mudanças Climáticas (IPCC) apresentou quatro cenários possíveis de mudanças climáticas (IPCC, 2013). Os cenários foram denominados, na sigla em inglês, de Representative Concentration Pathway (RCP). Cada cenário possui uma estimativa de emissão de gases de efeito estufa e de elevação da temperatura média global. Entre esses cenários estão o RCP 4.5 e o RCP 8.5 , considerados otimista e pessimista, respectivamente.

No Brasil, o modelo climático regional Eta, desenvolvido pelo Instituto Nacional de Pesquisas Espaciais (INPE), possui dados que foram aprimoradas de projeções climáticas do modelo climático global HadGEM2-ES do centro britânico Hadley Centre.

Denominado ETA-HadGEM2-ES, o modelo gerou dados de projeções climáticas com nível de detalhe baseado na resolução espacial de $20 \mathrm{~km}$, para os cenários climáticos RCP 4.5 e 8.5 definidos pelo IPCC, que representam condições de contorno pré-estabelecidas.

Os cenários climáticos são hipotéticos, dependentes da realização futura de variáveis como taxas médias de emissão de gases de efeito estufa, de crescimento populacional, padrões de consumo e consolidação de matrizes energéticas sustentáveis ou a base de combustíveis fósseis em escala mundial (IPCC, 2013).

Em sua maioria, os modelos climáticos que utilizam dados dos cenários RCP 4.5 e RCP 8.5 projetam aumento nas alturas médias de chuva para a região sul, o que é uma evidência de que haverá mais água disponível para ser armazenada nos reservatórios subterrâneos das bacias (TEBALDI et al., 2006; BATES et al., 2008).

A revisão geral sobre os impactos das mudanças climáticas nas águas subterrâneas nas regiões do Brasil mostra que até o ano de 2050 a região nordeste terá uma redução de $70 \%$ da recarga nos aquíferos em relação ao ano de 2010 (HIRATA; CONICELLI, 2012). Para a região sul haverá possibilidade de um aumento entre 30 e 100\% da recarga dos reservatórios subterrâneos até a metade do século XXI (MARENGO et al., 2007).

A bacia hidrográfica Alto Canoas, próxima à BHPM, foi investigada por meio da modelagem hidrológica a partir dos dados dos cenários de mudanças climáticas (RCP 4.5 e RCP 8.5). Os resultados apontaram para redução das vazões mínimas de referência Q95 e Q98 em ambos os cenários climáticos (NATEL, 2017).

As incertezas sobre a disponibilidade hídrica em bacias hidrográficas no futuro justificam a realização de estudos baseados em modelos hidrológicos associados a modelos climáticos.

O destaque deste estudo foi de utilizar o método Soil Moisture Accounting (SMA), na sigla em inglês, para simular os processos hidrológicos no solo. Esse é o principal método utilizado em modelagem de séries contínuas. Recentemente os autores Singh; Jain, (2015) e Awa; Ou; Raude, (2018) publicaram seus estudos com modelagem hidrológica a partir do método SMA.

Bennett; Peters, (2000), fizeram uma descrição detalhada do método SMA. Os autores fazem uma análise conceitual sobre o método e aplicação prática para duas bacias hidrográficas, uma bacia pequena $\left(1,92 \mathrm{~km}^{2}\right)$ com escoamentos reduzidos e localizada no estado do Texas nos Estados Unidos, e outra ba- 
cia com área mais significativa $\left(49,90 \mathrm{~km}^{2}\right)$ localizada na $\mathrm{Ge}$ órgia. O algoritmo obteve bom desempenho ao simular os processos hidrológicos nas bacias hidrográficas.

Fleming; Neary, (2004), explicam que para determinar os parâmetros necessários a execução do método SMA, o Sistema de Informação Geográfica (SIG), e a análise gráfica e analítica de séries de dados históricos da bacia, principalmente das séries de vazão, precipitação e evapotranspiração são opções possiveis para parametrizar o método SMA e obter desempenho satisfatório na modelagem.

O objetivo deste trabalho é apontar um prognóstico para as vazões de base de uma bacia hidrográfica, denominada bacia do rio Marombas, por meio da associação de um modelo hidrológico de base física com um modelo climático.

\section{CARACTERIZAÇÃO DA ÁREA DE ESTUDO}

A área de estudo é a bacia hidrográfica da estação fluviométrica Passo Marombas (BHPM), localizada no Rio Marombas, na região serrana de Santa Catarina, próximo de sua foz com o Rio Canoas, do qual é seu afluente. A bacia possui $3.678 \mathrm{~km}^{2}$ de área, distribuída entre as coordenadas geográficas $26^{\circ} 45^{\prime} 20^{\prime \prime}$ e $27^{\circ} 21^{\prime} 00^{\prime \prime}$ de latitude sul e entre $51^{\circ} 02^{\prime} 10^{\prime \prime}$ e $50^{\circ} 10^{\prime} 35^{\prime \prime}$ de longitude oeste (Figura 1).

A precipitação média anual é de $1500 \mathrm{~mm}$, sendo que nos meses mais chuvosos pode atingir até $150 \mathrm{~mm}$ mensais. O histórico climatológico mostra que a precipitação é bem distribuída durante todo o ano (EMBRAPA, 2012) (Figura 2).

Figura 1 - Bacia hidrográfica da estação fluviométrica Passo Marombas

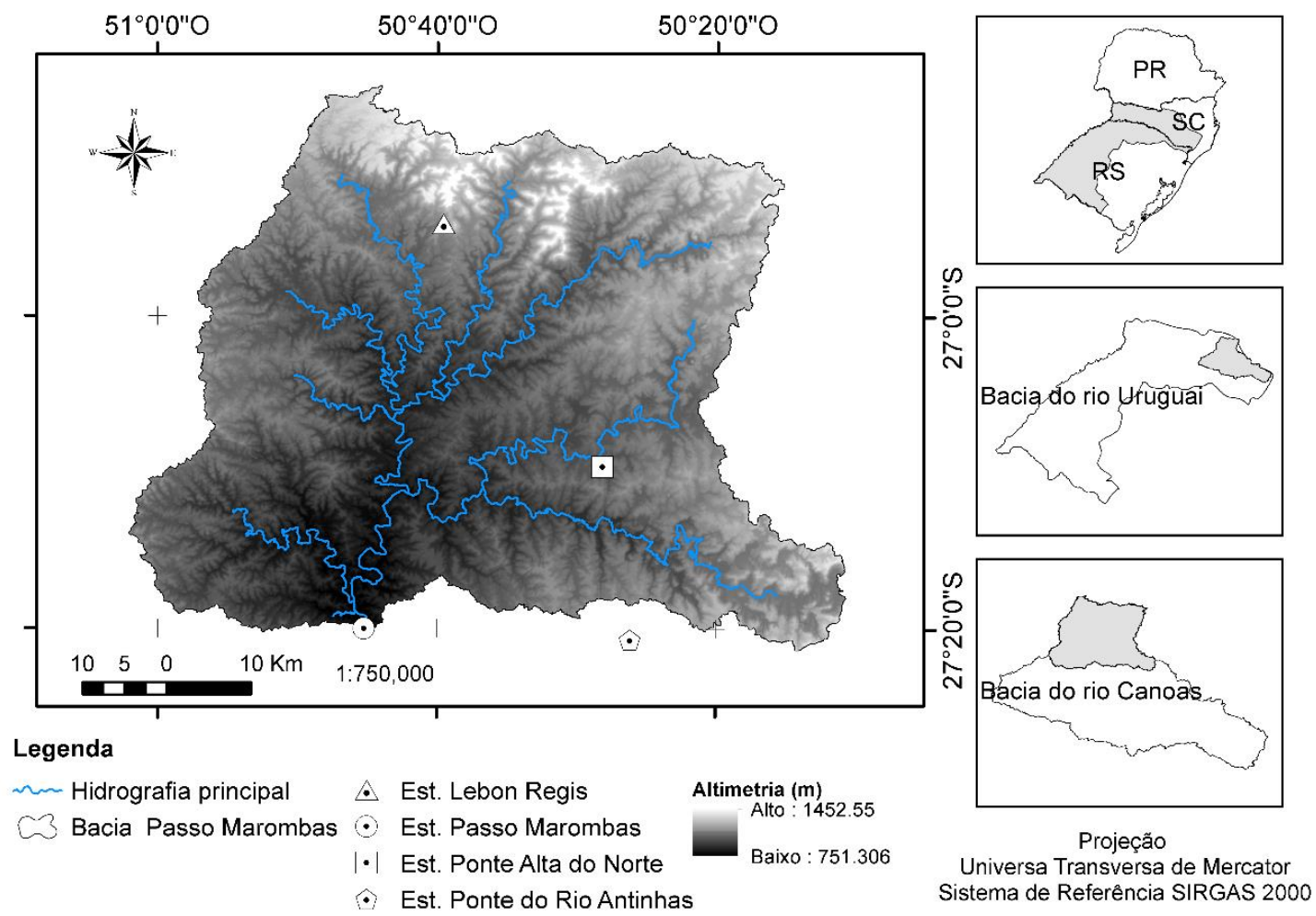

Fonte: Elaborado pelos autores (2020).

Figura 2 - Parâmetros climáticos médios da região de estudo

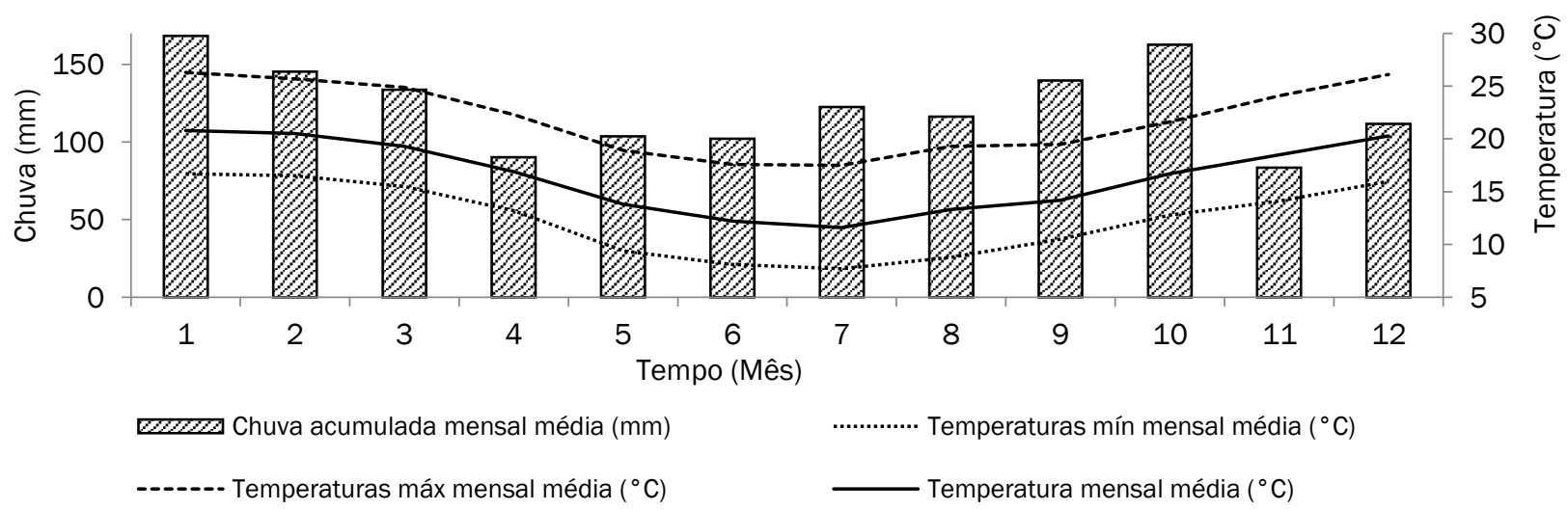

Fonte: Adaptado de EMBRAPA (2012). 
O relevo da BHPM é classificado como forte-ondulado e ondulado (EMBRAPA, 2004). As classes de solo que predominam são o Nitossolo Háplico, Cambissolo Húmico e Cambissolo Háplico, que juntas correspondem a 87,91\% da área total.

Uma avaliação preliminar sobre a evolução do uso do solo na BHPM entre os anos 1986, 2002 e 2017 revelou que as áreas agrícolas, compostas essencialmente por grãos, aumentaram $17 \%$ entre 1986 e 2017. Por outro lado, houve redução de $16 \%$ da área de mata nativa, composta por Floresta Ombrófila Mista. No mesmo período, a classe campo, composta por pastagens nativas ou cultivadas, reduziu cerca de $23 \%$, enquanto a classe reflorestamento, aumentou aproximadamente $21 \%$.

\section{MATERIAL E MÉTODOS}

A metodologia geral do trabalho está representada na figura 3. Um modelo hidrológico foi empregado para representar a fase terrestre do ciclo hidrológico e um modelo climático para a fase atmosférica deste ciclo. O prognóstico das vazões de base foi construído sob dois cenários climáticos: um cenário otimista, denominado RCP 4.5, e um cenário pessimista, denominado RCP 8.5, projetados pelo modelo ETA-HadGEM2-ES. O primeiro pode ser considerado um cenário conservador, em termos de alterações na temperatura média terrestre, com aumentos entre $1,1^{\circ} \mathrm{C}$ e $2,6^{\circ} \mathrm{C}$, até o fim do século XXI. O segundo projeta um aumento na temperatura média global entre $2,6^{\circ} \mathrm{C}$ e $4,8^{\circ} \mathrm{C}$, no mesmo período (IPCC, 2013).

Os parâmetros adotados para avaliar as vazões de base simuladas em ambos os cenários foram as vazões mínimas de referência Q98, $_{95}$, Q90 e média anual das vazões de base, de 2020 a 2099 (especificamente nos futuros centrados nos anos de 2030, 2050, 2070, 2090). Estes parâmetros foram comparados com o período base (1977-1990), tomado como testemunha, em função de estar dentro do período considerado de normal climatológica (1961 a 1990) (OMM, 1989).

Figura 3 - Fluxograma geral da metodologia do estudo

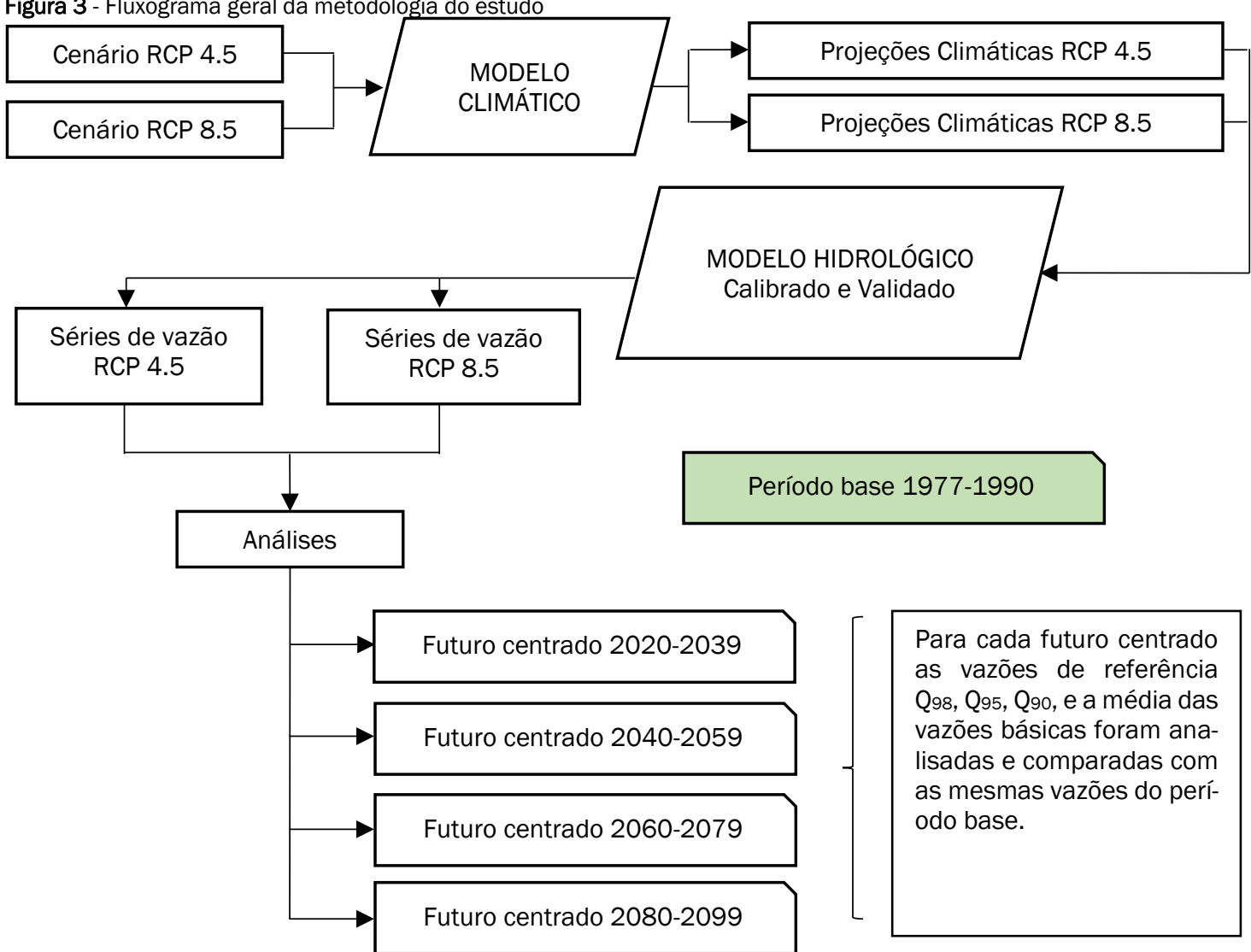

Fonte: Elaborado pelos autores (2020).

As séries de precipitação e evapotranspiração real projetadas pelo modelo ETA-HadGEM2-ES, para os cenários de RCP 4.5 e RCP 8.5, foram aplicadas como entradas no modelo hidrológico (chuva-vazão) Hydrologic Engineering Center - Hydrologic Modeling System (HEC-HMS). Este modelo foi calibrado e validado com os períodos de dados observados de 14 anos (01/01/1977 a 31/12/1990) e 06 anos (01/01/1992 a $31 / 12 / 1997)$, respectivamente. Os períodos foram definidos por serem os mais longos e contínuos disponíveis.

\subsection{O modelo ETA-HadGEM2-ES}

O modelo climático ETA-HadGEM2-ES do Instituto Nacional de Pesquisas Espaciais (INPE) é um Modelo Climático Regional na sigla em inglês (RCM), proveniente do detalhamento de um Modelo Global do Clima (GCM) denominado de HadGEM2-ES. Os GCM's têm origem na previsão numérica de tempo e representam as interações gerais que ocorrem entre os componentes do sistema climático global, atmosfera e oceano, associado a uma representação básica da superfície terrestre. Os 
RCM's associam a solução numérica dos GCM's a dados detalhados de relevo e vegetação de uma determinada região para produzir informações mais detalhadas.

Os dados de projeções do modelo ETA-HadGEM2-ES são largamente empregados em estudos no Brasil. Ainda, as séries projetadas passaram por correção de viés, conforme método descrito por OLIVEIRA et al., (2015). O procedimento objetivou reduzir as incertezas associadas aos dados projetados pelo modelo climático para a região da BHPM.

\subsection{Unidades de respostas hidrológicas - URH`s}

O modelo hidrológico foi aplicado numa estratégia de análise do todo pelo estudo de suas partes, com o objetivo de estruturar a simulação hidrológica da área da bacia e, deste modo, obter melhor representatividade do comportamento hidrológico como um todo. Deste modo, a BHPM foi discretizada em 20 Unidades de Resposta Hidrológica (URH), definidas a partir de geoprocessamento do Modelo Digital de Terreno (MDT) (SDS, 2013) da área de estudo, com resolução espacial horizontal de 5 metros e vertical de 0,3 metros, do uso e ocupação da terra e do conhecimento tácito sobre a região. Resultaram dez sub-bacias hidrográficas e dez interbacias hidrográficas (BACK, 2004).

\subsection{Processos simulados pelo modelo hidrológico}

Os processos do ciclo hidrológico simulados pelo HEC-HMS foram: a) interceptação ou acúmulo de água da chuva pela vegetação (Canopy Method); b) retenção e detenção superficiais de água nas depressões do terreno (Surface Method); c) infiltração, percolação e armazenamento de água no solo (Loss Method); d) escoamento superficial (Transform Method); e) escoamento de base (Baseflow Method); e e) propagação nos canais (Routing Method) (USACE, 2015c).

Para cada processo, o modelo utiliza um conjunto de mínimo de parâmetros para sua execução, cujo valores iniciais fornecidos pelo usuário podem ser otimizados, a critério.

\subsection{Método Soil Moisture Accounting SMA de simulação da hidrologia subterrânea}

0 algoritmo SMA simula os fluxos sub-superficiais e subterrâneos, o que inclui as vazões de base. O SMA utiliza uma série de reservatórios de armazenamento para simular o volume atual de água em cada componente terrestre do ciclo hidrológico (Figura 4).

Os valores dos parâmetros dos métodos que simulam as componentes do ciclo hidrológico, Canopy Method; Surface Method; Loss Method; Transform Method; Baseflow Method; Routing Method, foram obtidos a partir de geoprocessamento de dados espaciais da bacia em ambiente Sistema de Informações Geográficas (SIG), como Modelo Digital de Terreno (SDS, 2013), Mapas de Tipo do Solo (EMBRAPA, 2004), Imagens Orbitais, entre outros.

Além disso, séries de dados históricos observados na bacia como histogramas e hidrogramas também foram utilizados para definição dos parâmetros dos métodos conforme feito por Fleming; Neary, (2004).

\subsection{Calibração, validação e desempenho do modelo hidroló- gico}

A calibração automática e validação do modelo hidrológico foi realizada para os períodos de 01/01/1977 a 31/12/1990 e 01/01/1992 a 31/12/1997, respectivamente. Nestes períodos é observada a variabilidade hidrológica na bacia por possuir vazões de magnitudes diferentes, incluindo vazões máximas e mínimas extremas.

O método utilizado para a calibração disponível no HEC-HMS foi o Unvariate-Gradiente Algorithm. Esse método faz sucessivas correções nos parâmetros do modelo a partir de um processo iterativo.

Os dados de vazão, chuva e evapotranspiração utilizados na calibração e validação estão em escala diária e foram obtidos a partir de estações pluviométricas e fluviométricas disponíveis (Tabela 1). A espacialização das estações pode ser observada na Figura 1. 
Figura 4 - Esquema conceitual para aplicação do método SMA de modelagem hidrológica
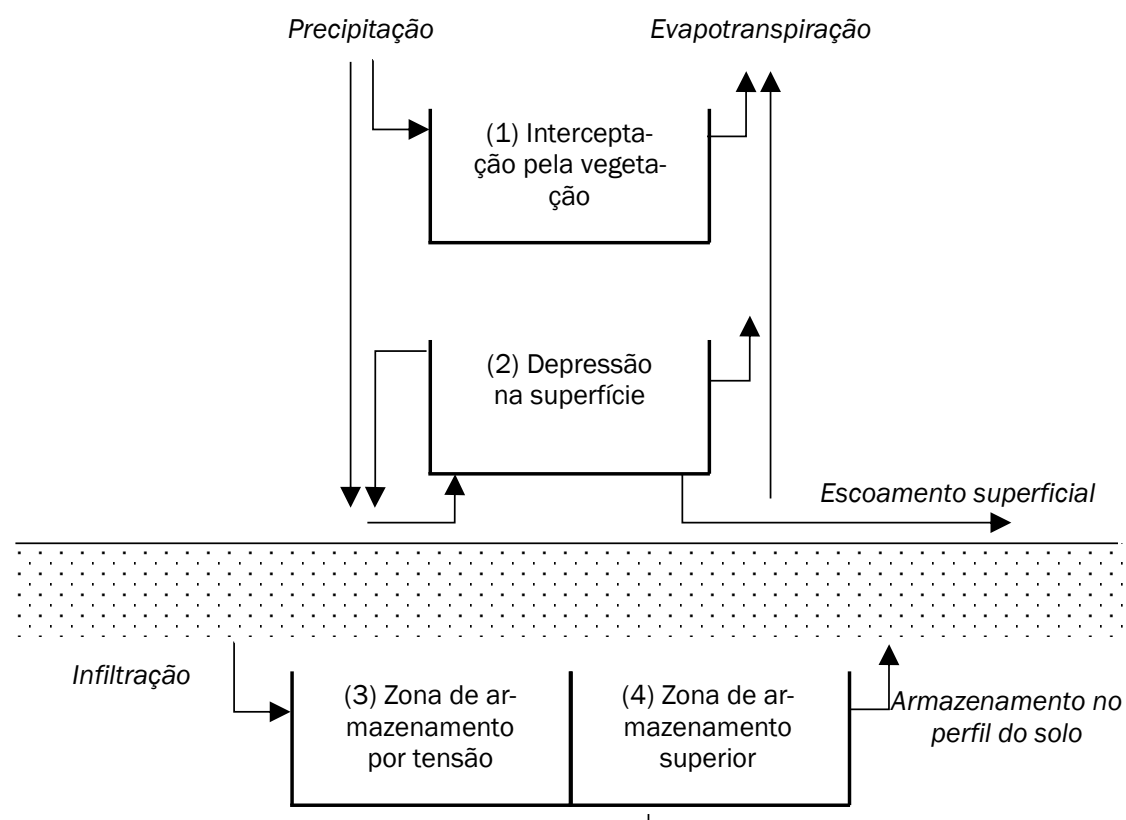

Percolação

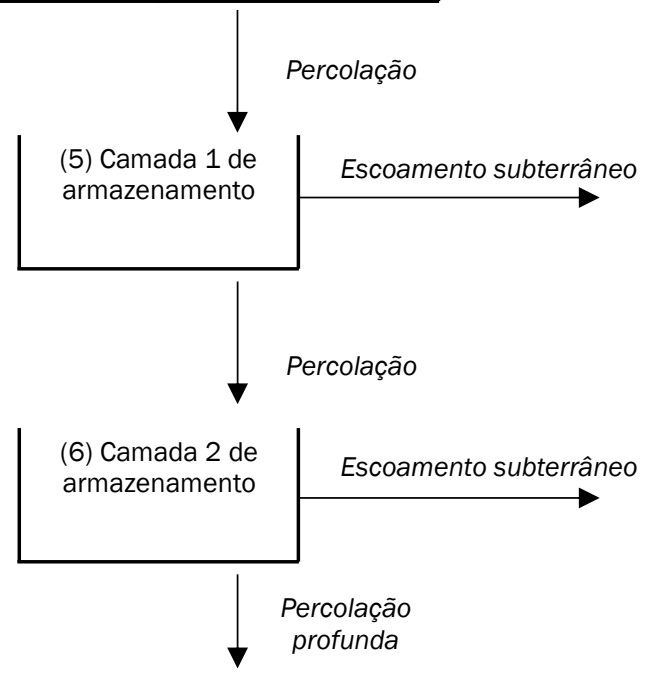

Fonte: Adaptado de USACE (2015b).

Tabela 1 - Estações de dados hidrológicos

\begin{tabular}{|c|c|c|c|c|}
\hline Nome da Estação & Tipo & Código & Latitude & Longitude \\
\hline Passo Marombas & Fluviométrica & 71498000 & $27^{\circ} 20^{\prime} 02^{\prime \prime S}$ & $50^{\circ} 45^{\prime} 12^{\prime \prime} 0$ \\
\hline Passo Marombas & Pluviométrica & 2750009 & $27^{\circ} 20^{\prime} 02 " S$ & $50^{\circ} 45^{\prime} 12^{\prime \prime} 0$ \\
\hline Lebon Regis & Pluviométrica & 2650019 & $26^{\circ} 54^{\prime} 06^{\prime \prime} \mathrm{S}$ & $50^{\circ} 39^{\prime} 33^{\prime \prime} 0$ \\
\hline Ponte Alta do Norte & Pluviométrica & 2750010 & $27^{\circ} 09^{\prime} 40^{\prime \prime} \mathrm{S}$ & $50^{\circ} 28^{\prime} 08^{\prime \prime} 0$ \\
\hline Ponte Rio Antinhas & Pluviométrica & 2750012 & $27^{\circ} 20^{\prime} 43^{\prime \prime} \mathrm{S}$ & $50^{\circ} 26^{\prime} 09^{\prime \prime} 0$ \\
\hline
\end{tabular}

Fonte: Elaborado pelos autores (2020).

0 peso ponderado de cada estação pluviométrica nas áreas das sub-bacias e interbacias da área de estudo foi calculado por meio da aplicação da técnica dos polígonos de Thiessen. A estação com maior peso sobre a área de estudo é a estação Lebon Régis, com índice de 0,399, seguida pelas estações Ponte Alta do Norte com 0,285, Passo Marombas com 0,226 e Ponte Rio Antinhas com 0,089 em relação a área total da BHPM.

A Evapotranspiração Potencial (ETP), que representa uma das saídas de água da bacia ou interbacia, foi calculada para o período de 1977-1990, para uso na calibração do modelo hidrológico. Os dados da estação meteorológica da EPAGRI/CIRAM/INMET localizada no município de Lages, foram utilizados para aplicação do método Penman-Monteith de cálculo da
ETP devido à falta de dados climáticos disponíveis em estações instaladas na área de estudo.

O uso de dados da estação meteorológica de Lages não implica em incertezas significativas sobre os resultados obtidos, uma vez que a estação está localizada na região hidrográfica da qual a BHPM faz parte.

Quatro métricas estatísticas foram usadas para avaliar o desempenho (performance) do modelo hidrológico. Estas foram separadas em dois grupos, o primeiro corresponde ao erro do modelo em relação aos dados medidos. Assim, foi usado o Root-mean-square error to the standard deviation of measured data (RSR) (Equação 1) e o Percent Bias Statistic (PBIAS) (Equação 2). 


$$
\begin{aligned}
& \mathrm{RSR}=\sqrt{\frac{\sum_{\mathrm{i}=1}^{\mathrm{n}}\left(\mathrm{Q}_{\text {obs }_{\mathrm{i}}}-\mathrm{Q}_{\text {sim }_{\mathrm{i}}}\right)^{2}}{\sum_{\mathrm{i}=1}^{\mathrm{n}}\left(\mathrm{Q}_{\text {obs }_{\mathrm{i}}}-\mathrm{Q}_{\text {méd }_{\mathrm{obs}}}\right)^{2}}} \\
& \mathrm{P}_{\mathrm{BIAS}}=\left(\frac{\sum_{\mathrm{i}=1}^{\mathrm{n}} \mathrm{Q}_{\mathrm{sim}_{\mathrm{i}}}-\sum_{\mathrm{t}=1}^{\mathrm{n}} \mathrm{Q}_{\mathrm{obs}_{\mathrm{i}}}}{\sum_{\mathrm{t}=1}^{\mathrm{n}} \mathrm{Q}_{\mathrm{obs}}}\right)
\end{aligned}
$$

O Segundo representa a concordância entre o modelo hidrológico e os dados observados. Dessa maneira, foi empregado o Coeficiente de determinação (R2) (Equação 3) e o Coeficiente de eficiência de Nash-Sutcliffe (NSE) Equação (4) e Log NashSutclife (NSELog) Equação (5).

$$
\mathrm{R}^{2}=\frac{\sum_{\mathrm{t}=1}^{\mathrm{n}}\left(\mathrm{Q}_{\text {obs }_{\mathrm{i}}}-\mathrm{Q}_{\text {méd }_{\text {obs }}}\right)\left(\mathrm{Q}_{\text {sim }_{\mathrm{i}}}-\mathrm{Q}_{\text {méd }_{\text {sim }}}\right)^{2}}{\sum_{\mathrm{i}=1}^{\mathrm{n}}\left(\mathrm{Q}_{\text {obs }_{\mathrm{i}}}-\mathrm{Q}_{\text {méd }_{\text {obs }}}\right)^{2} * \sum_{\mathrm{i}=1}^{\mathrm{n}}\left(\mathrm{Q}_{\text {sim }_{\mathrm{i}}}-\mathrm{Q}_{\text {méd }_{\text {sim }}}\right)^{2}}
$$

$$
\begin{aligned}
& \text { NSE }=1-\frac{\sum_{\mathrm{i}=1}^{\mathrm{n}}\left(\mathrm{Q}_{\mathrm{obs}_{\mathrm{i}}}-\mathrm{Q}_{\text {sim }_{\mathrm{i}}}\right)^{2}}{\sum_{\mathrm{i}=1}^{\mathrm{n}}\left(\mathrm{Q}_{\mathrm{obs}_{\mathrm{i}}}-\mathrm{Q}_{\text {méd }_{\mathrm{obs}}}\right)^{2}} \\
& \mathrm{NSE}_{L o g}=1-\frac{\sum_{\mathrm{i}=1}^{\mathrm{n}}\left(\mathrm{Q}_{\mathrm{obs}, \log _{\mathrm{i}}}-\mathrm{Q}_{\mathrm{sim}, \log _{\mathrm{i}}}\right)^{2}}{\sum_{\mathrm{i}=1}^{\mathrm{n}}\left(\mathrm{Q}_{\mathrm{obs}, \log _{\mathrm{i}}}-\mathrm{Q}_{\text {méd } \left._{\mathrm{obs}, \log _{\mathrm{i}}}\right)^{2}}\right.}
\end{aligned}
$$

O coeficiente de Nash-Suticliffe (NS) é referência para qualificação de modelos hidrológicos (BRIGHENTI; BONUMÁ; CHAFFE, 2016).

Moriasi (2007), apresenta as faixas dos indicadores NSE, RSR e PBIAS com suas respectivas classificações de qualidade (Tabela 2).

Tabela 2 - Índices utilizados para aferir a eficácia do modelo hidrológico

\begin{tabular}{cccc}
\hline Qualidade da representação & RSR & NSE & PBIAS (\%) \\
\hline Muito bom & $0,00<\mathrm{RSR}<0,50$ & $0,75<\mathrm{NSE} \leq 1,00$ & PBIAS $< \pm 10$ \\
Bom & $0,50<\mathrm{RSR}<0,60$ & $0,65<\mathrm{NSE} \leq 0,70$ & $\pm 10<\mathrm{PBIAS}< \pm 15$ \\
Satisfatório & $0,60<\mathrm{RSR}<0,70$ & $0,50<\mathrm{NSE} \leq 0,65$ & $\pm 15 \leq \mathrm{PBIAS} \leq \pm 2$ \\
Insatisfatório & $\mathrm{RSR}>0,70$ & $\mathrm{NSE} \leq 0,00$ & PBIAS $\geq \pm 25$ \\
\hline
\end{tabular}

Fonte: Adaptado de Moriasi (2007).

\subsection{Análises do impacto das mudanças climáticas na hidrolo- gia subterrânea da BHPM}

As análises do impacto das mudanças climáticas na hidrologia subterrânea da BHPM consistiram na comparação gráfica e absoluta da variação das vazões de referência, consideradas vazões mínimas e vazão básica média.

As comparações foram realizadas entre os futuros centrados 2030 (2020 a 2039), 2050 (2040 a 2059), 2070 (2060 a 2079) e 2090 (2080 a 2099), e o período base (1977 a 1990). As diferenças nas vazões de referência e vazões básicas nos períodos centrados em relação ao período base puderam ser quantificadas.

As vazões mínimas de referência Q90, Q95 e Q98 foram calculadas porque são fundamentais para o processo de gestão dos recursos hídricos.

A vazão de base média anual em cada período também foi utilizada para avaliar os efeitos das mudanças climáticas sobre a hidrologia subterrânea da BHPM. Estas foram calculadas por meio do método de separação do escoamento de base do escoamento total aplicado a séries diárias.

O filtro numérico digital de ECKHARDT (2005) foi escolhido por ser mais representativo em bacias onde o escoamento subterrâneo contribui com boa parte do escoamento total (COLLISCHONN e FAN, 2013). A equação de filtragem do escoamento de base é dada por ECKHARDT (2005) (Equação 6).

$$
b_{i}=\frac{\left(1-B F I_{\max }\right) \cdot a \cdot b_{i-1}+(1-a) \cdot B F I_{\max } \cdot y_{i}}{1-a \cdot B F I_{\max }}
$$

Onde $b_{i}$ é o escoamento subterrâneo no instante $i, b_{i}-1$ é o escoamento subterrâneo no instante $i-1, y_{i}$ é o escoamento total no instante $i, a=e^{\frac{-\Delta \mathrm{t}}{k}}$ sendo que $\Delta \mathrm{t}$ é a variação do tempo entre duas observações e outra e $k$ é a constate de recessão do escoamento de base (Equação 7).

$$
k=\frac{-\Delta \mathrm{t}}{\ln \frac{Q_{(t+\Delta \mathrm{t})}}{Q_{(t)}}}
$$

O filtro de Eckhardt considera o índice de fluxo de base máximo $B F I_{\text {max }}$. Este índice define o máximo percentual de escoamento de base que deve separar do escoamento total. Seu valor pode ser calculado submetendo as vazões de referência $Q_{90}$ e $Q_{50}$ a equação abaixo (Equação 8).

$$
B F I_{\max }=0,8344 \cdot \frac{Q_{90}}{Q_{50}}+0,2146
$$

Esta equação pode gerar valores para $B F I_{\max }$ contínuos o que permite aumentar o desempenho do filtro de Eckhardt (COLLISCHONN e FAN, 2013).

\section{RESULTADOS E DISCUSSÃO}

\subsection{Calibração e validação e desempenho do modelo hidro- lógico}

A calibração e validação do modelo apresentou resultados adequados, confirmados pelas métricas estatísticas (Tabela 3). As Figuras 5 e 6, apresentam uma comparação gráfica entre os hidrogramas das vazões simuladas e observadas. 


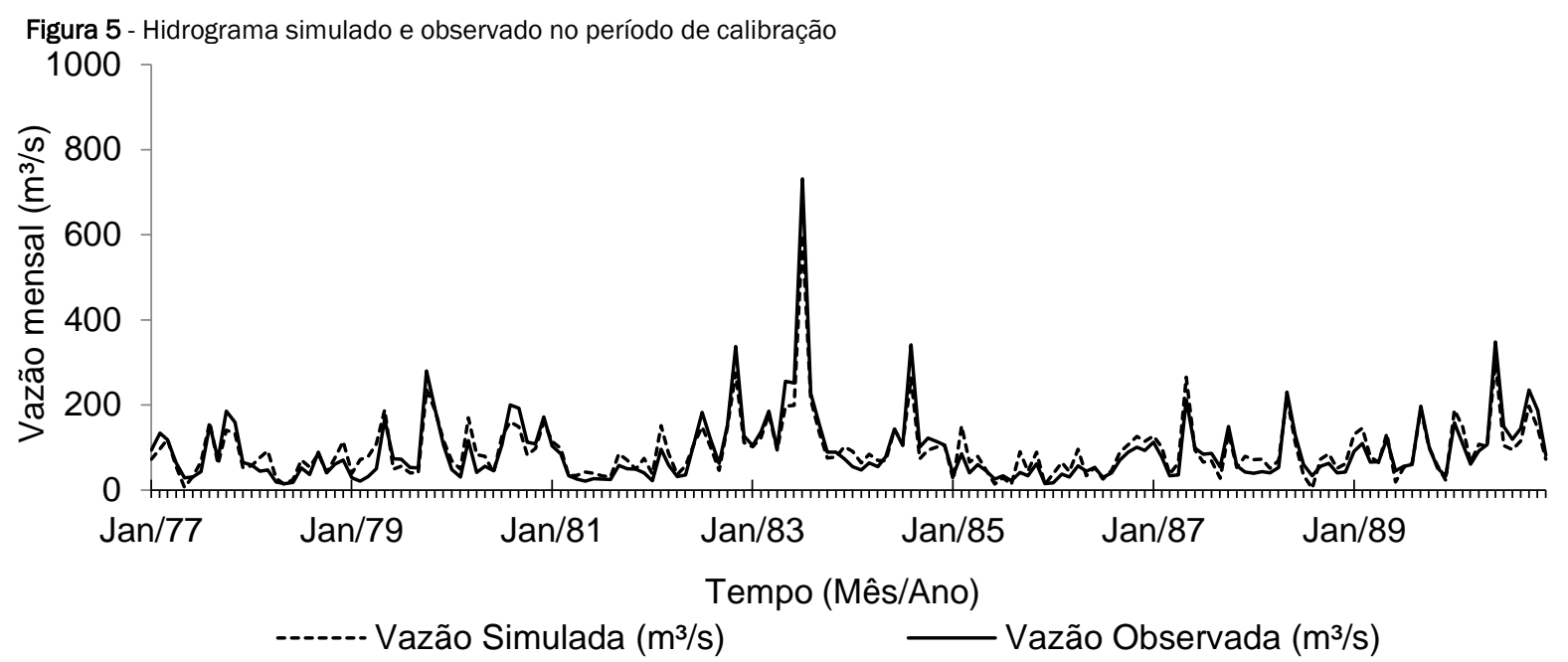

Fonte: Elaborado pelos autores (2020).

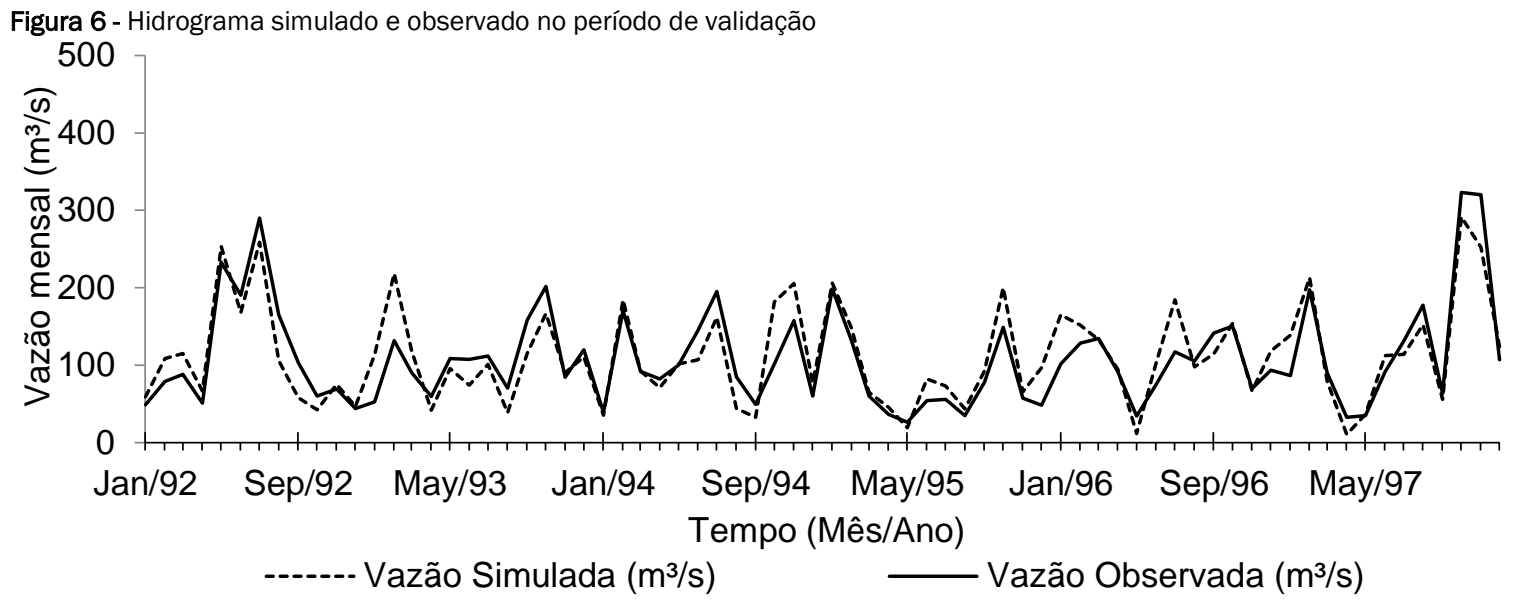

Fonte: Elaborado pelos autores (2020).

A comparação gráfica entre as séries simuladas e observadas nos períodos de calibração e validação permite observar que o modelo obteve bom desempenho.
As métricas estatísticas demonstraram que o modelo é qualificado, tanto para calibração quanto para validação (MORIASI, 2007) (Tabela 3).

Tabela 3 - Valores das métricas de desempenho do modelo

\begin{tabular}{cccccc}
\hline \multirow{2}{*}{ Etapa da Modelagem } & \multicolumn{3}{c}{ Métrica de Desempenho } \\
& NSE & LogNSE & RSR & PBIAS & R2 \\
\hline Calibração & 0,87 & 0,70 & 0,40 & 1,81 & 0,79 \\
Validação & 0,77 & 0,67 & 0,50 & 2,75 & 0,79 \\
\hline
\end{tabular}

Fonte: Elaborado pelos autores (2020).

\subsection{Variação futura nas vazões mínimas de referência e va- zão básica média}

A variação futura nas vazões mínimas de referência e vazão básica média estão diretamente relacionadas com a quantidade e distribuição da chuva sobre a BHPM, que poderá variar por causa das alterações climáticas (MARENGO; TOMASELLA; NOBRE; 2010).
As Tabelas 4 e 5 apresentam os percentuais de variação das vazões projetadas pelo modelo hidrológico em relação ao período base (1977-1990). O resultado mostra que para o cenário RCP 4.5 não haverá redução das vazões, o que se observa é um aumento nas vazões mínimas de referência e vazão de base média. 0 cenário RCP 8.5 mostra uma redução principalmente nas vazões $Q_{98}$ e $Q_{95}$ nos futuros centrados em 2030 e 2050 , seguido de aumento nos futuros centrados em 2070 e 2090. 
Tabela 4 - Variação percentual nas vazões de referência e vazão de base média nos futuros centrados em relação ao período base para o cenário climático RCP4.5

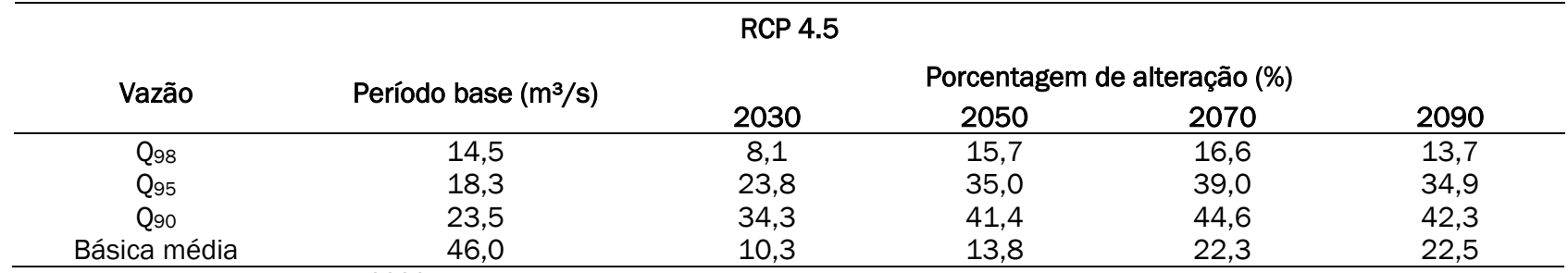

Fonte: Elaborado pelos autores (2020).

Tabela 5 - Variação percentual nas vazões de referência e vazão de base média nos futuros centrados em relação ao período base para o cenário climático RCP8.5

RCP 8.5

\begin{tabular}{cccccc} 
Vazão & \multicolumn{5}{c}{ Porcentagem de alteração (\%) } \\
& Período base $\left(\mathbf{m}^{\mathbf{3}} / \mathbf{s}\right)$ & $\mathbf{2 0 3 0}$ & $\mathbf{2 0 5 0}$ & $\mathbf{2 0 7 0}$ & $\mathbf{2 0 9 0}$ \\
\hline Q98 $_{98}$ & 14,5 & $-39,0$ & $-39,9$ & 31,7 & 10,3 \\
Q95 & 18,3 & $-20,5$ & $-13,4$ & 46,6 & 31,7 \\
Q90 & 23,5 & $-4,1$ & 4,1 & 52,3 & 42,6 \\
Básica média & 46,0 & 10,3 & 12,2 & 28,3 & 41,7 \\
\hline
\end{tabular}

Fonte: Elaborado pelos autores (2020).

A redução percentual de 39 e 20,5\% nas vazões referência Q98 e Q95 para o período de 2020 a 2039, seguida por redução de 39,9 e 13,4\% para o período de 2040 a 2059, em relação ao período base de 1977-1990, representa a situação futura mais crítica em termos de disponibilidade hídrica. Figura $7[A]$ e [B]. Nesse mesmo período a vazão de base média apresenta aumento percentual de 10,3 e 12,2\% (Figura 8).

O aumento na vazão de base média sugere que o armazenamento subterrâneo não será impactado pelas mudanças climáticas em ambos os cenários, apesar de a simulação indicar redução para as vazões mínimas de referência $Q_{98}$ e $Q_{95}$ no cenário RCP 8.5.

Considerando que a revisão de bibliográfica realizada por Hirata; Conicelli (2012) revelou um aumento de 30 a 100\% da recarga dos reservatórios subterrâneos da região sul até a metade do século XXI, os dados para vazão de base média se mostram alinhados com estudos já realizados.

A explicação para a redução das vazões de referência mínimas Q98 e Q95 e aumento da vazão de base média verificado nos futuros centrados 2030 e 2050, pode estar relacionado com a má distribuição da chuva, pois as projeções climáticas do modelo sugerem um aumento nos volumes de chuva para o sul do Brasil até o final do século XXI (MARENGO et al., 2007; TEBALDI et al., 2006; BATES et al., 2008).

A má distribuição da chuva poderá resultar em aumento no número de eventos extremos com grandes volumes precipitados em um curto espaço de tempo, e eventos de estiagem concentrados. Com estiagens mais severas as vazões nos rios devem diminuir de forma drástica por tempo determinado e como consequência disto, as estatísticas das vazões mínimas de referência devem ser alteradas, como observado na redução das vazões Q98 e Q95. Por outro lado, os eventos extremos de chuvas com grandes volumes deverão recarregar os reservatórios subterrâneos, o que pode explicar o aumento da vazão de base média.

Para o cenário climático RCP 4.5 há tendência de aumento geral das vazões mínimas de referência, mais discreto para Q98 em relação a Q95 e Q9o, que apontam incrementos de 39,0 e 44,6\% respectivamente para o futuro centrado 2070 (Figura 7).

A vazão de base média não registra variações significativas em função de ser um cenário ameno quanto as mudanças climáticas, não havendo uma tendência de fortes mudanças na distribuição espacial e temporal da chuva. Apesar da magnitude do impacto das mudanças climáticas nas vazões básicas da BHPM ser distinta entre os cenários RCP 4.5 e RCP 8.5, a variabilidade climática reforça a hipótese de que a hidrologia subterrânea das bacias será impactada, como já se observa em estudos realizados em diferentes locais do mundo.

Considerando que na BHPM predomina o aquífero Serra Gera com alto potencial para armazenamento de água, pode-se inferir que a bacia possui vulnerabilidade para as alterações climáticas.

Nas figuras 7 e 8, pode-se verificar a variação nas vazões mínimas de referência $Q_{98}, Q_{95}$ e $Q_{90}$ nos futuros centrados para os cenários RCP 4.5 e RCP 8.5 . 
Figura 7 - Variação da Q98 [A], Q95 [B] Q90 [C]no futuro para os cenários RCP4.5 e RCP8.5 em relação ao Período Base 20

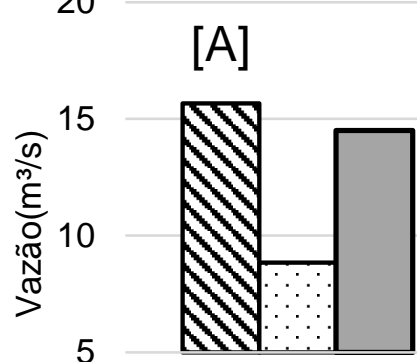

2020-2039

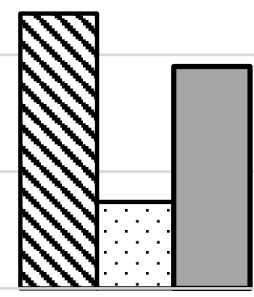

2040-2059

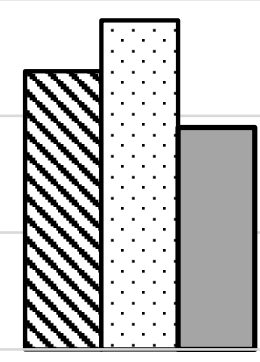

2060-2079

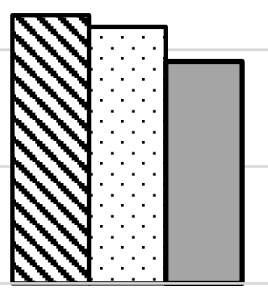

2080-2099

هRCP 4.5 घRCP 8.5 aPeríodo base

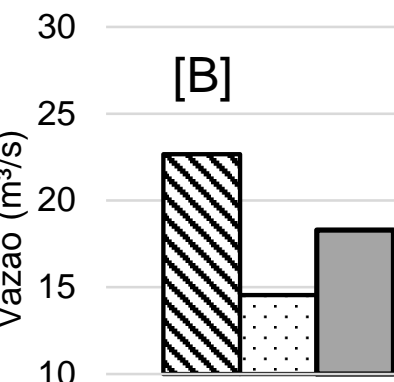

2020-2039

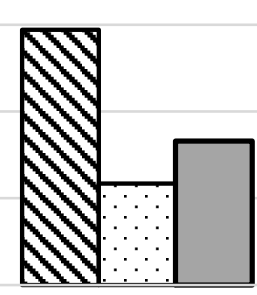

2040-2059

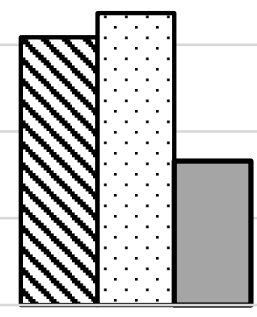

2060-2079

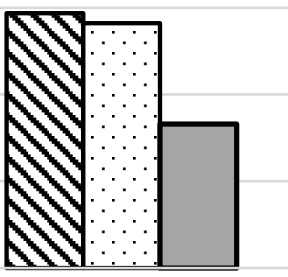

2080-2099

बRCP 4.5 aRCP 8.5 aPeríodo base Período

40

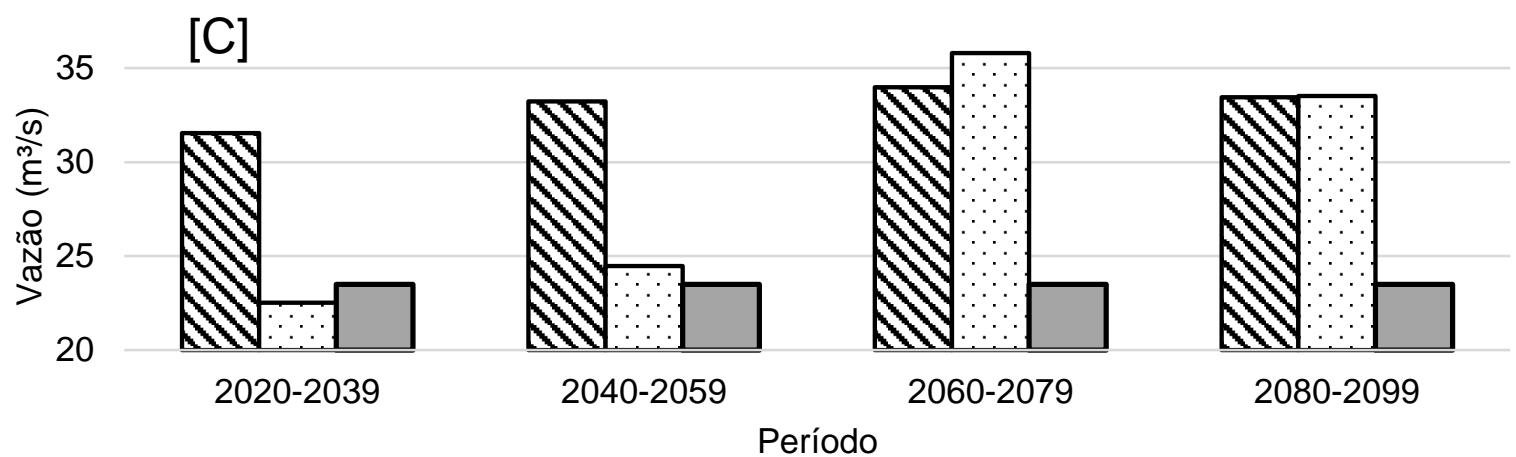

vRCP 4.5 वRCP 8.5 口Período base

Fonte: Elaborado pelos autores (2020).

Figura 8 - Variação da vazão básica média nos futuros centrados para os cenários RCP4.5 e RCP8.5 em relação ao Período Base 70

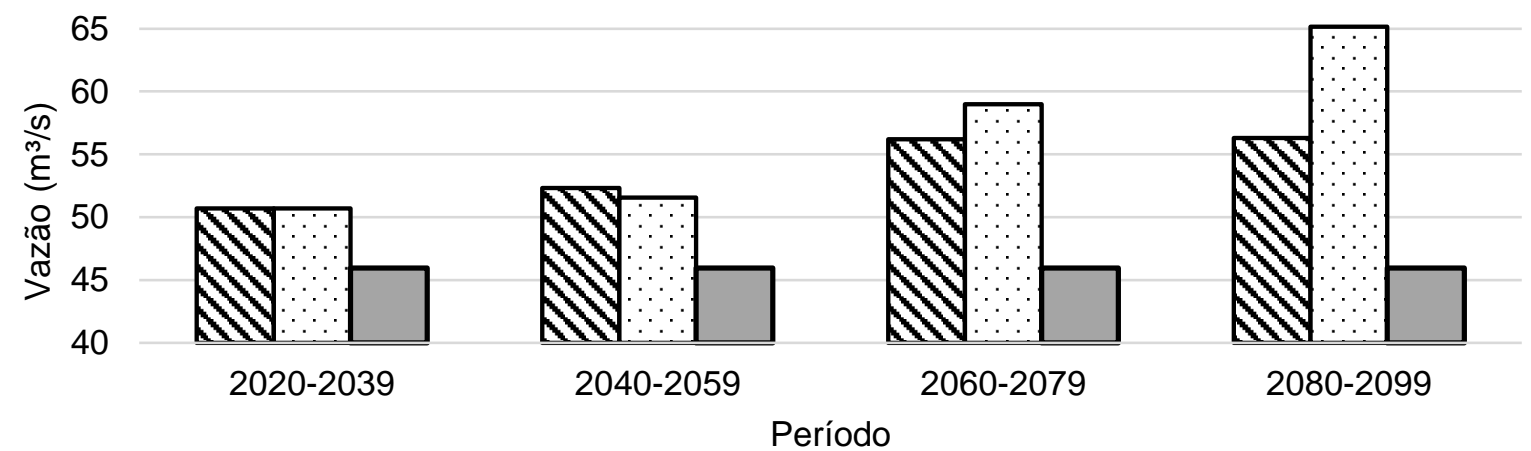

s RCP 4.5 aRCP 8.5 aPeríodo base

Fonte: Elaborado pelos autores (2019). 
Figura 9 - Comparação entre curvas de permanência do período base e períodos dos futuros centrados em 2030, 2050, 2070 e 2090 para o cenário RCP 4.5

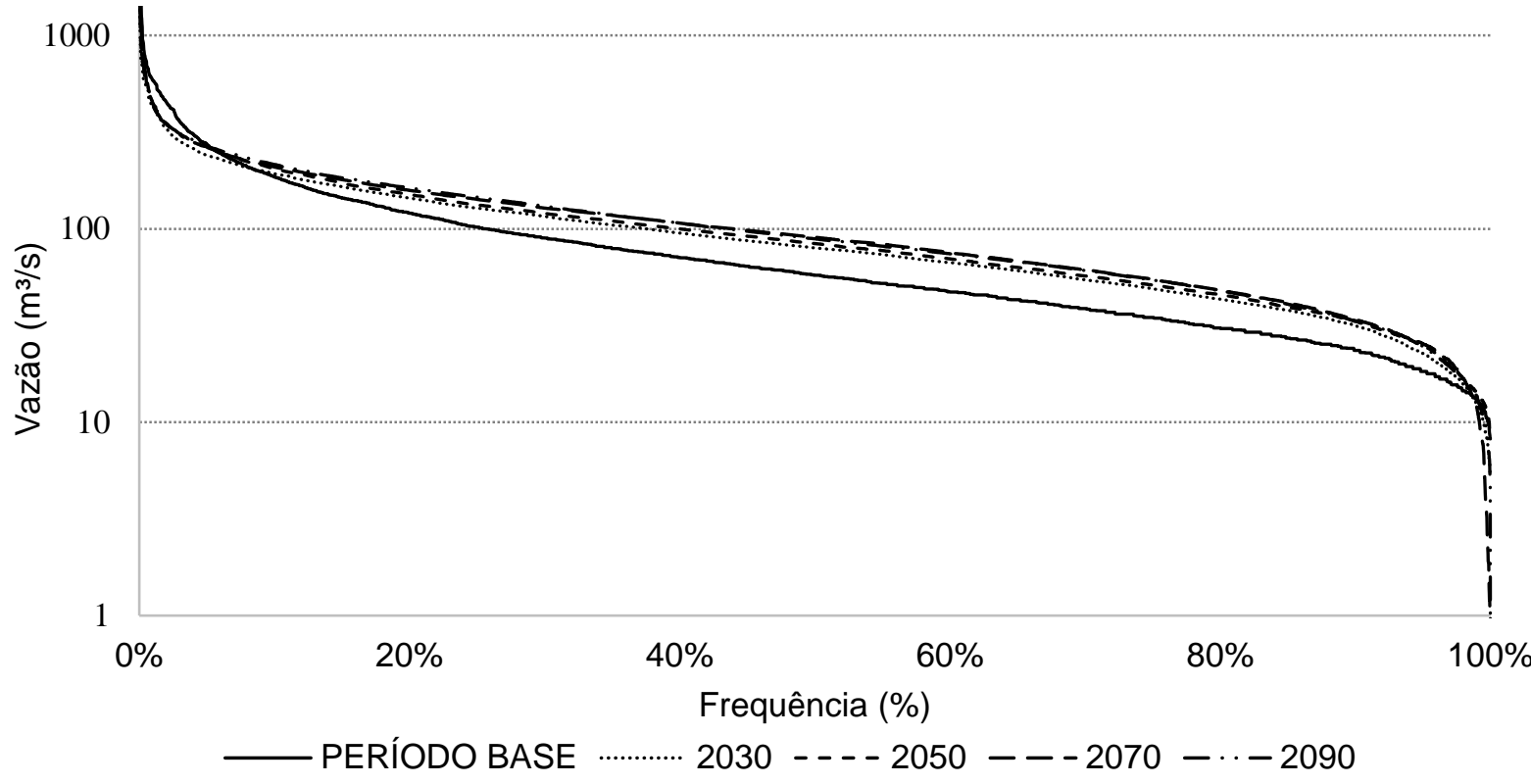

Fonte: Elaborado pelos autores (2020).

Figura 10 - Comparação entre curvas de permanência do período base e períodos dos futuros centrados em 2030, 2050, 2070 e 2090 para o cenário RCP 8.5

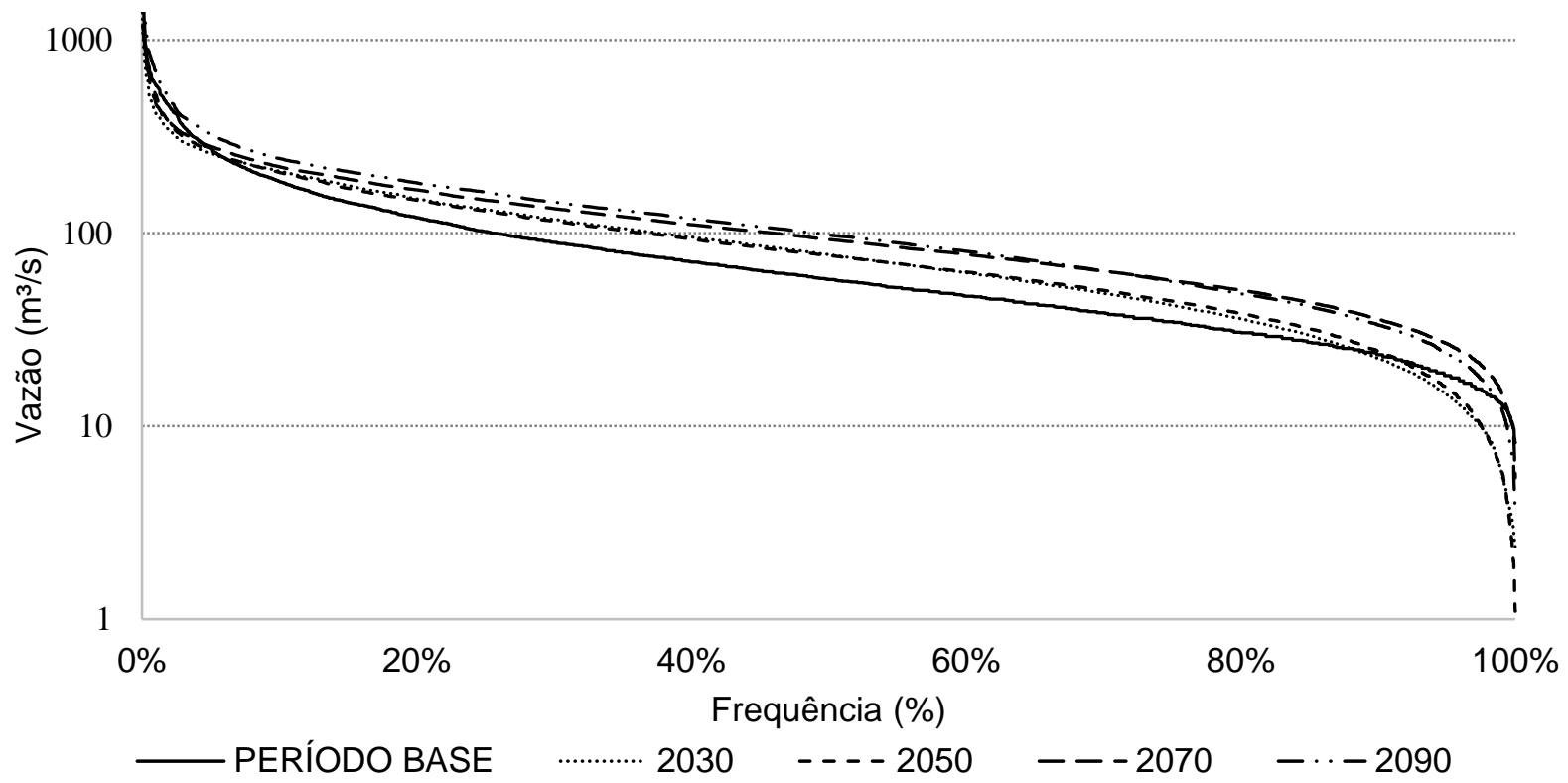

Fonte: Elaborado pelos autores (2020).

O aumento nas vazões mínimas de referência $Q_{98}, Q_{95}$ e $Q_{90}$ cria condições para ampliação de processos econômicos e sociais que demandam água, portanto é positivo para a bacia, inclusive para a manutenção de seus processos hidrológicos e ecológicos.

Além do efeito das mudanças climáticas, a variação das vazões tem relação com alterações na morfologia das bacias hidrográficas, a exemplo do uso e ocupação da terra (FAN et al., 2014).
0 aumento significativo de florestas plantas por exemplo, como o caso da área de reflorestamento na BHPM que aumentou $21 \%$ entre 1986 e 2017, merece atenção no contexto dos recursos hídricos. Pesquisadores que utilizaram o método de bacias pareadas para avaliar o efeito das florestas nas vazões, afirmam que o excesso de floresta resulta na diminuição das vazões médias e de base (ANDREÁSIAM, 2004; CHANG, 2006; ZHAO et al., 2012). 
Este argumento é fortalecido pelo fato de as árvores possuírem raízes profundas e, portanto, conseguirem ter acesso a água armazenada nas camadas mais profundas do solo, mantendo suas taxas de evapotranspiração constantes durantes períodos secos (BROOKS et al., 2003).

Portanto a combinação das mudanças climáticas e alterações antrópicas na morfologia das bacias hidrográficas são fatores determinantes que explicam a variabilidade hídrica em sistemas naturais.

O efeito da variação quantitativa, espacial e temporal da chuva sobre a BHPM, deverá ser o principal fator responsável pela alteração nas vazões de referência. Considerando a relação de dependência entre as variáveis chuva e vazão, a contribuição deste trabalho está na quantificação destas variações ao longo do tempo futuro.

\section{CONCLUSÃO}

A avaliação dos impactos das mudanças climáticas na hidrologia da BHPM para os cenários de mudanças climáticas RCP 4.5 e RCP 8.5 definidos pelo IPCC, é positiva para o cenário RCP 4.5 uma vez que as vazões mínimas de referência Q98, Q95 e Q90 e a vazão básica média, em todos os períodos dos futuros centrados, serão superiores em comparação ao período base. Neste cenário pode-se concluir que a magnitude com que as alterações climáticas hipoteticamente ocorrerão, resultarão em aumento da disponibilidade hídrica o que é positivo para o meio ambiente e para gestão dos recursos hídricos.

Para o cenário RCP 8.5, a variação relativa da $Q_{98}$ nos futuros centrados em relação ao período base com destaque para uma redução drástica de 39,0\% e 39,9\% nos futuros centrados em 2030 e 2050, é conclusiva da variabilidade do sistema hidrológico na BHPM provocado principalmente pelas mudanças climáticas.

No caso das vazões básicas médias os resultados apontam para um aumento geral em ambos os cenários de mudanças climáticas, portanto a extrema baixa disponibilidade hídrica deverá ocorrer em períodos de estiagens curtos e concentrados alterando a estatística das vazões básicas médias.

O maior impacto será observado na Q98 considerando o cenário RCP 8.5. Este cenário deverá exigir maior esforço por parte do poder público no sentido de garantir a gestão dos recursos hídricos, uma vez que a Q98 é uma das principais vazões de referência para outorga de recursos hídricos.

\section{REFERÊNCIAS}

ANA - Agencia Nacional de Aguas. Manual de procedimentos técnicos e administrativos de outorga de direito de uso de recursos hídricos da Agência Nacional de Águas. ANA, Brasília, 2013, 249 p.

ANDREÁSSIAN, V. Water and Forest: From historic controversy to scientific debate. Journal of Hydrology, v. 291, p. 1-27, 2004. https://doi.org/10.1016/i.jhydrol.2003.12.015
AWA, W.; OU, A.; RAUDE, J. M. Continuous Modeling of the Mku rumudzi River Catchment in Kenya Using the HEC-HMS Conceptual model: Calibration, Validation, Model Performance Evaluation and Sensitivity Analysis, 2018.

BATES, B. C.; KUNDZEWICZ, Z. W.; WU, S.; PALUTIKOF, J. P. Climate Change an water: technical paper of the intergovernmental panel on climate change, IPCC, Geneva, 2008. 210 p.

BENNETT, T.; PETERS, J. Continuous soil moisture accounting in the hydrologic engineering center hydrologic modeling System (HEC-HMS). ASCE Technical Publication, v. 8806, n. 1, p. 1-10, 2000. https://doi.org/10.1061/40517(2000)149

BRASIL. Ministério do Meio Ambiente dos Recursos Hídricos e da Amazônia Legal. Lei n. 9.433: Política Nacional de Recursos Hídricos. Brasília: Secretaria de Recursos Hídricos, 1997. $72 \mathrm{p}$.

BRIGHENTI, T. M.; BONUMÁ, N. B.; CHAFFE, P. L. B. Calibração hierárquica do modelo swat em uma bacia hidrográfica catarinense. Revista Brasileira de Recursos Hídricos, v. 21, n, 1, p.53-65, 2016. https://doi.org/10.21168/rbrh.v21n1.p53$\underline{64}$

BROOKS, K. N.; FFOLLIOT, P. F.; GREGERSEN, H. M.; DEBANO, L. F. Hydrology and the management of watersheds. Blackwell. 2003. $574 \mathrm{p}$.

COLLISCHONN, W.; FAN, F. M. Defining parameters for Eckhardt's digital baseflow filter. Hydrological Process. https://doi.org/10.1002/hyp.9391. 2013.

COLLISCHONN, W.; DORNELLES, F. Hidrologia: para Engenharia e Ciências Ambientais. Porto Alegre, RS: Abrh, 2013. 350 p.

CHANG, M. Forest Hydrology: an introduction to water and forest. 2ed2 Taylor \& Francis, 2006.

DÖLL P. Vulnerability to the impact of climate change on renewable groundwater resources: a global-scale assessment. Environ Res Lett, 2009. 12 p. https://doi.org/10.1088/17489326/4/3/035006

EMBRAPA - EMPRESA BRASILEIRA DE PESQUISA AGROPECUÁRIA. Levantamento de reconhecimento dos solos do Estado de Santa Catarina. Rio de Janeiro: Embrapa Solos, 2004. mapa, Escala 1:250.000.

EMBRAPA. Atlas climático da região Sul do Brasil: Estados do Paraná, Santa Catarina e Rio Grande do Sul. Marcos Silveira Wrege ... [et al.], editors técnicos. - Brasília, DF: Embrapa, 2012. ISBN 978-85-7035-013-8.

FAN, F. M. et al. Simulação da Superfície de Equilíbrio de Água Subterrânea Aproximada em Escala Regional. RBRH, v. 19, p. 263-276, 2014. https://doi.org/10.21168/rbrh.v19n3.p263-276

FICKLIN, D. L.; ROBESON, S. M.; KNOUFT, J. H. Impacts of recent climate change on trends in baseflow and stormflow in 
United States watersheds. Geophysical Research Letters, v. 43, n. 10, p. 5079-5088, 2016. https://doi.org/10.1002/2016GL069121

FLEMING, M. Continuous Hydrologic Modeling with HMS: Parameter Estimation and Model Calibration and Validation. Cookeville, TN: Texas Technological University, 2004.

HIRATA, R.; CONICELLI, B. P. Groundwater resources in Brazil: A review of possible impacts caused by climate change. Anais da Academia Brasileira de Ciencias, v. 84, n. 2, p. 297-312, 2012. $\underline{37652012005000037}$

IPCC. The physical Science basis. In: Climate Change 2013: Working group I contribution to the fifth assessment report of the intergovernmental panel on climate change. IPCC, Geneva. 2013.

JARSJÖ, J.; ASOKAN, S. M.; PRIETO, C.; BRING, A.; DESTOUNI, G. Hydrological responses to climate change conditioned by historic alterations of land-use and water-use. Hydrologyand Earth System Sciences, v. 16, 1335-1347, 2012. https://doi.org/10.5194/hess-16-1335-2012

JORGE SANTOS, P.V.C.; CUNHA, A.C. Outorga de Recursos Hídricos e Vazão Ambiental no Brasil: Perspectivas Metodológicas Frente ao Desenvolvimento do Setor Hidrelétrico na Amazônia. Revista Brasileira de Recursos Hídricos, v.18, n.3, p. 81-95, 2013. https://doi.org/10.21168/rbrh.v18n3.p81-95

MARENGO, J. A. Mudanças climáticas globais e seus efeitos sobre a biodiversidade - caracterização do clima atual e definição das alterações climáticas para o território brasileiro ao longo do século XXI. 2. ed. Brasília: Ministério do Meio Ambiente, 2006. v.1, p.214.

MARENGO, José A.; TOMASELLA, Javier; NOBRE, Carlos A. Mudanças Climáticas e Recursos Hídricos. In: BICUDO, Carlos E.de M.; TUNDISI, J. G.. J.G.; SCHEUENSTUHL, M.C.B. (Orgs). Águas do Brasil: análises estratégicas. São Paulo: Instituto de Botânica, 2010.

MORIASI, D. N. et al. Model evaluation guidelines for systematic quantification of accuracy in watershed simulation. Transaction of th ASABE, v. 50, n 3, p. 885-9000, 2007. https://doi.org/10.13031/2013.23153

NATEL DE MOURA, C. Impactos hidrológicos de mudanças climáticas na bacia hidrográfica do Alto Canoas, SC. Lages , 2017. 124 p.

NETO, S. L. R.; SÁ, E. A. S.; DEBASTIANI, A. B.; et al. Efficacy of rainfall-runoff models in loose coupling spacial decision support systems modelbase. Water Resources Management. v. 33, n. 3. p. 889-904. https://doi.org/10.1007/s11269018-2086-2

NYENJE, P. M.; BATELAAN, O. Estimating the effects of climate change on groundwater recharge and baseflow in the upper Ssezibwa catchment, Uganda. Hydrological Sciences Journal, v. $54, \quad$ n. $4, \quad$ p. $713-726,2009$. https://doi.org/10.1623/hysj.54.4.713

ORGANIZAÇÃO METEOROLÓGICA MUNDIAL. Calculation of monthly and annual 30-year standard normals. Geneva, 1989. (WMO. Technical document, n. 341; WCDP, n.10).

OLIVEIRA, G. G.; PEDROLLO, O. C.; CASTRO, N. M. R. Stochastic approach to analyzing the uncertainties and possible changes in the availability of water in the future based on scenarios of climate change. Hydrológy and Earth System Sciences, v. 19, n. 8, p. 3585-3604, 2015. https://doi.org/10.5194/hess-19$\underline{3585-2015}$

SDS. Levantamento aerofotogramétrico de Santa Catarina. Estado de Santa Catarina, Secretaria de Desenvolvimento Econômico Sustentável do Estado De Santa Catarina (SDS/SC). Florianópolis, 2013.

SINGH, W. R.; JAIN, M. K. Continuous Hydrological Modeling using Soil Moisture Accounting Algorithm in Vamsadhara River Basin, India. Journal of Water Resource and Hydraulic Engineering, v. 4, n. 4, p. 398-408, 2015. https://doi.org/10.5963/JWRHE0404011

TAN, T. C. et al. Salt release from yellow alkaline noodles. International Food Research Journal, v. 24, n. 1, p. 318-326, 2017.

TEBALDI, C. et al. Going to the extremes an intercomparison of model-simulated historical and future changes in extreme events. Climatic Change, n.79, p. 185-211, 2006. https://doi.org/10.1007/s10584-006-9051-4

TUCCI, C. E. M. Modelos Hidrológicos. 2. ed. Porto Alegre: UFRGS/ABRH, 1998.

USACE - U. S. ARMY CORPS OF ENGINEERS. Hydrologic Modeling System HEC-HMS: User Manual, version 4.1. Davis: US Army Corps of Engineers, Hydrologic Engineering Center, 2015c. 600p.

ZHAO, F; XU, Z.; ZHANG, L. Changes in streamflow following vegetation changes from paired catchments. Hydrological Processes, v.26, p. 1561-1573, 2012. https://doi.org/10.1002/hyp.8266

ZUCCO, E.; PINHEIRO, A.; DESCHAMPS, F. C.; SOARES, P. A. Metodologia para estimativa das concentrações em cursos de agua para vazões de referência: uma ferramenta de suporte e apoio ao sistema de gestão de bacias hidrográficas. Revista de Gestão de Águas da América Latina, v. 9, n.1, p. 25-37, 2012. https://doi.org/10.21168/rega.v9n1.p25-37

WITTENBERG, H. Effects of season and man-made changes on baseflow and flow recession: case studies. v. 2123, n. December 2002, p. 2113-2123, 2003. https://doi.org/10.1002/hyp.1324

WINTER, T. The concept of hydrologic landscapes. Journal of the American Water Resources Association. v. 37, n. 2. 2001. p. 335-349. https://doi.org/10.1111/i.17521688.2001.tb00973.x 